\title{
A Device for Scheduling Irrigation in Fruit Tree Orchards from Sap Flow Readings
}

\author{
J.E. Fernández, A. Diaz-Espejo, M.V. Cuevas \\ and J.C. Montaño \\ Instituto de Recursos Naturales y Agrobiología \\ Apartado 1052, 41080-Sevilla \\ Spain
}

\author{
R. Romero and J.L. Muriel \\ CICE, IFAPA, Las Torres \\ Carretera Sevilla-Alcalá del Río \\ Alcalá del Río, Sevilla \\ Spain
}

Keywords: Olea europaea, control, transpiration, soil evaporation, irrigation dose

\begin{abstract}
The aim of this work was to design and test a controller (CRP) able to calculate the irrigation dose automatically, suitable for high frequency irrigation in fruit tree orchards. The device consisted of three (replicates) measuring units (MU), a control unit (CU) and a pump and electrovalve controller (PEC). The MUs collected information on the transpiration $\left(E_{\mathrm{p}}\right)$ dynamics within the orchard, with the compensation heat-pulse method. Each MU made sap flow readings in one normally-irrigated (NI) tree and in one over-irrigated (OI) tree used for reference. The time course of the $E_{\mathrm{pNI}} / E_{\mathrm{pOI}}$ ratio was used by the $\mathrm{CU}$ for calculating the irrigation dose (ID) daily. The system was programmed to apply a deficit irrigation in which the trees were bound to use part of the readily available water in the soil. Laboratory tests showed a high performance of the CRP for amplifying and filtering output signals from the sap flow probes. The field test showed the CRP was able to collect and handle sap flow data, to calculate ID according to the design algorithm, and to control the pump and electrovalve for supplying the desired ID to the experimental plot. Whether the use of the CRP means an improvement on irrigation scheduling, as compared to standard methods, was not evaluated in this work.
\end{abstract}

\section{INTRODUCTION}

Among the new approaches to optimize irrigation scheduling in fruit tree orchards, trunk diameter variations and sap flow readings are considered to be promising methods (Jones, 2004). A crucial advantage of using any of these plant-based indicators for irrigation scheduling is that they can be automatically monitored.

The potential for assessing the tree response to irrigation based on continuous monitoring of trunk diameter by linear variable displacement transducers (LVDT sensors) has been evaluated in a variety of fruit tree species. An example of irrigation control based on the use of LVDT sensors in almond trees was published by Goldhamer and Fereres (2004). Sap flow readings are mainly used to determine water consumption and the dynamics of tree transpiration, as well as water uptake by main roots. Among the different sap flow methods, the compensation heat-pulse method (CHP) has been used in several fruit tree species, including olive (Fernández et al., 2006a,b; Giorio and Giorio, 2003; Williams et al., 2004), the species considered in this work.

Most currently available irrigation controllers require the irrigation dose (ID) to be calculated and input by the user. Some new devices are able to calculate ID by themselves, based on measurements of soil matric potential (Luthra et al., 1997; Klein, 2004; Miranda et al., 2005) or volumetric soil water content (Nogueira et al., 2002). 
These automatic irrigation controllers (AIC) are relatively inexpensive, user-friendly devices, but have limitations derived from soil moisture monitoring. To our knowledge, an AIC based either on LVDT or sap flow readings has not yet been developed, although irrigation protocols based on both approaches have been suggested (Fernández et al., 2001; Goldhamer and Fereres, 2004). Nadezhdina and Cermak (1997) reported on an AIC based on what they call Sap Flow Index but, to our knowledge, a commercial version has not been released.

The aim of this work was to design an AIC for fruit tree orchards based on sap flow measurements in the trunk of representative trees, and to test its performance both for acquiring and manipulating sap flow data and for calculating ID according to a designed algorithm.

\section{MATERIALS AND METHODS}

\section{Controller hardware}

We have named the AIC evaluated in this work CRP (Controlador de Riego de la Plantación). It was designed and built in our laboratory, for controlling high frequency irrigation in fruit tree orchards. It has three main physical components:

a) The Measurement Unit (MU). This is the part of the CRP installed in the orchard for sap flow readings with the CHP method (Green, 1998). Each MU measures sap flow in a normally-irrigated (NI) tree and in an over-irrigated (OI) tree. The CRP tested here had three MUs, each with three sets of heat-pulse velocity (HPV) probes (Tranzflo NZ Ltd, Palmerston North, New Zealand) per tree. Main characteristics of the probes are described in Green et al. (2003). Each set of probes had temperature probes inserted at $x^{\prime}=5 \mathrm{~mm}$ upstream and $x=10 \mathrm{~mm}$ downstream from the heater, with thermocouples at 5, 12, 22 and $35 \mathrm{~mm}$ below the cambium. The time delays for the temperatures at points $x$ ' and $x$ to become equal, i.e. the $t_{\mathrm{z}}$ values, were derived after the firing of each heat pulse, which happened for $1 \mathrm{~s}$ every $30 \mathrm{~min}$, throughout the testing period. Output voltages from the HPV probes were filtered and amplified by an ICL7650B high performance amplifier and an OP07 ultra low offset voltage operational amplifier. A potentiometer was included to correct the amplification offset. Eventually, a second order Butterworth Low-Pass Filter reduced noise and multiplied the signal by a factor of 2. All these components were implemented in an electronic board for each probe set.

b) The Control Unit (CU). This is a standard PC wired to each of the three MUs. The RS485 protocol was used for communication between CU and the MUs. Every day at $2345 \mathrm{~h}, \mathrm{CU}$ received the $t_{\mathrm{z}}$ values measured by each MU on the day, and used them to calculate the sap flow values $\left(Q, \mathrm{~L}_{\text {hour }}{ }^{-1}\right)$ for each HPV probe set and measuring time. From these values $\mathrm{CU}$ calculated the total daily transpiration of each tree $\left(E_{\mathrm{p}}, \mathrm{L}\right.$ day $\left.^{-1}\right)$. Then CU used the $E_{\mathrm{p}}$ values as described in the next section to calculate ID.

c) The Pump and Electrovalves Controller (PEC). This device, wired to the CU, switched the irrigation pump on and off, and opened and closed the electrovalve of the experimental sector of the orchard for enough time to supply the ID calculated by CU.

\section{Calculation of the irrigation dose}

When irrigating with the CRP, the irrigation dose applied to the OI trees (ID $\mathrm{OI}_{\mathrm{I}}$ ) is always greater than that supplied to the NI trees (ID $\mathrm{NI}_{\mathrm{NI}}$ ). This is because the OI trees must be over-irrigated to ensure their transpiration is not limited by a lack of water in the soil, 
while the ID supplied to the NI trees is enough just to replace the crop water needs, or even less than that, if a deficit irrigation strategy is chosen.

The soil in the orchard must be around field capacity on the first two days of the irrigation period. On these two days, ID must be given by the user. At $2345 \mathrm{~h}$ on the second day after starting the irrigation period, CU collected the $t_{\mathrm{z}}$ values from each $\mathrm{MU}$ and calculated the $E_{\mathrm{p}}$ value of that day, for each NI tree $\left(E_{\mathrm{pNI}}\right)$ and each OI tree $\left(E_{\mathrm{pOI}}\right)$. Then, $\mathrm{CU}$ calculated $E_{\mathrm{pNI}} / E_{\mathrm{pOI}}$. The following day $\mathrm{CU}$ did the same and, this time, compared the resulting $E_{\mathrm{pNI}} / E_{\mathrm{pOI}}$ value to that of the previous day. From this comparison $\mathrm{CU}$ adjusted automatically ID for the next day: if $\left(E_{\mathrm{pNI}} / E_{\mathrm{pOI}}\right)_{\mathrm{DOY}} \cong\left(E_{\mathrm{pNI}} / E_{\mathrm{pOI}}\right)_{\mathrm{DOY}-1 \text {, where }}$ DOY is day of the year, the ID supplied on the current day could have been either enough to cover the water needs of the NI trees, or too high. Therefore, CU reduced ID for the next day. If $\left(E_{\mathrm{pNI}} / E_{\mathrm{pOI}}\right)_{\mathrm{DOY}} \neq\left(E_{\mathrm{pNI}} / E_{\mathrm{pOI}}\right)_{\mathrm{DOY}-1}, \mathrm{CU}$ assumed the ID supplied on the current day was not enough to cover the demand of the NI trees, and increased ID for the next day.

The threshold value from which $\left(E_{\mathrm{pNI}} / E_{\mathrm{pOI}}\right)_{\mathrm{DOY}}$ must be considered as different from $\left(E_{\mathrm{pNI}} / E_{\mathrm{pOI}}\right)_{\mathrm{DOY}-1}$ is defined by the user. For the field test shown in this work, we programmed $\mathrm{CU}$ to consider the transpiration ratios as different when $\left(E_{\mathrm{pNI}} / E_{\mathrm{pOI}}\right)_{\mathrm{DOY}}<1.05\left(E_{\mathrm{pNI}} / E_{\mathrm{pOI}}\right)_{\mathrm{DOY}-1}>\left(E_{\mathrm{pNI}} / E_{\mathrm{pOI}}\right)_{\mathrm{DOY}}$. Thus, when the difference was greater than $5 \%, \mathrm{CU}$ automatically reduced ID by $10 \%$ on the first day $\left(E_{\mathrm{pNI}} / E_{\mathrm{pOI}}\right)_{\mathrm{DOY}} \neq\left(E_{\mathrm{pNI}} / E_{\mathrm{pOI}}\right)_{\mathrm{DOY}-1}$, and by $20 \%$ on the following days. When the difference was lower than $5 \%$, CU automatically increased ID by $10 \%$ on the first day and by $20 \%$ on the subsequent days. The relatively big threshold value of 5\% was intended for achieving a deficit irrigation approach, in which the crop used part of the readily available water in the soil.

\section{Controller software}

Each MU contained a PIC18F4525 microcontroller programmed in C language. This device controlled both the firing of heat-pulses and the collection of differential temperatures (differences in temperature between the downstream and upstream thermocouples). After each heat-pulse was fired, the $t_{\mathrm{z}}$ values were derived and saved in the external EEPROM located in the MU board out of the microcontroller.

A Visual Basic application was designed for the CU to operate. This allowed for configuration of parameters related to the HPV probe characteristics and location in the stem. For sap flow calculations, wound width and correction factors were chosen according to calibration experiments made with olive (Fernández et al., 2006b). With the application implemented in CU we were able to plot and save differential temperatures read by the HPV probes, which helped to detect probe malfunctions.

The software for the PEC was written in C language, then compiled into a hex file and finally loaded to a PIC16F877 microcontroller. At the time fixed for starting irrigation ( $800 \mathrm{~h}$ in our case), CU sent the calculated ID to PEC, and the software generated the orders needed to open the electrovalve and to run the pump. Water was applied for time enough to supply ID. Besides, the PEC read pulses from a flow meter installed after the electrovalve. Additional functionality was programmed to allow configuration of main parameters from a remote PC connected to Internet.

The system was programmed to display error messages immediately a malfunction is detected. If the system is left unattended, the user may not be aware of the error messages and the system may become chaotic. To avoid that, we supplied a data base to the $\mathrm{CU}$, with acceptable limits above and below a mean ID value for each day of the 
irrigation season. These ID values were estimated for the orchard conditions, according to the crop coefficient approach recommended by the FAO (Allen et al., 1998; see Fernández et al., 2006a, for details), and with 34 years data (1971-2004) of main weather variables registered in the farm. Operation with the data base is optional. If used, CU compares the calculated ID value with that of the data base before connecting with the PEC: if within the limits, the calculated ID is sent to the PEC; if out of the limits, the ID value of the data base is sent to the PEC, instead of that calculated by the CRP.

\section{Field testing}

First testing of the CRP in the field was carried out in an olive orchard (Olea europaea 'Manzanilla de Sevilla') of La Hampa, an experimental farm of the Spanish Research Council (CSIC) close to Seville, in southwest Spain $\left(37^{\circ} 17^{\prime} \mathrm{N}, 6^{\circ} 3^{\prime} \mathrm{W}\right.$, elevation $30 \mathrm{~m}$ ). The trees, planted at $7 \mathrm{~m} \times 5 \mathrm{~m}$, were 38 years old. Values of volumetric soil water content $\left(\theta, \mathrm{m}^{3} \mathrm{~m}^{-3}\right)$ at $-0.03 \mathrm{MPa}$ and at $-1.5 \mathrm{MPa}$ are $0.20 \mathrm{~m}^{3} \mathrm{~m}^{-3}$ and $0.10 \mathrm{~m}^{3}$ $\mathrm{m}^{-3}$, respectively. The estimated rootzone depth was $1.6 \mathrm{~m}$.

We selected a plot with four rows of eight trees each, homogeneous in size, for irrigation by the CRP. In March 2006 we installed the three MUs in the plot, at about 50, 75 and $100 \mathrm{~m}$ from the CU. This was located behind a shelter covering the header of the irrigation system, next to the plot. For irrigating the NI trees we installed an irrigation system consisting of a single lateral per tree row with five $3 \mathrm{~L} \mathrm{~h}^{-1}$ drippers per tree, $1 \mathrm{~m}$ apart. As explained above, $\mathrm{ID}_{\mathrm{NI}}$ was calculated daily by the $\mathrm{CU}$, except for the two first days of the irrigation season, which began on 8 May, day of year (DOY) 128 .

Irrigation of the three OI trees was made with a second irrigation system. In this case, the emitters had a discharge rate of $6 \mathrm{~L} \mathrm{~h}^{-1}$. We irrigated the OI trees to $130 \%$ of the crop evapotranspiration $\left(\mathrm{ET}_{\mathrm{c}}, \mathrm{mm}\right)$ estimated with the crop coefficient approach and data from an automatic weather station next by the orchard. Values both of the crop coefficient $\left(K_{\mathrm{c}}\right)$ and the coefficient related to the percentage of ground covered by the crop $\left(K_{\mathrm{r}}\right)$ were previously derived for the orchard conditions (Fernández et al., 2006a). Values of $E_{c}$ were calculated twice a week during the whole testing period, being ID $_{\mathrm{OI}}$ adjusted accordingly. We used a standard irrigation controller (Agronic 4000, Sistemes Electrònics PROGRÉS, S.A., Lérida, Spain) for supplying the calculated $\mathrm{ID}_{\mathrm{OI}}$. Measurements of $\theta$ were made once a week in all NI and OI trees, with a neutron probe (0.2-1.6 m depth) and gravimetrically $(0.0-0.2 \mathrm{~m}$ depth$)$.

\section{RESULTS AND DISCUSSION}

Fig. 1 shows the lower and upper limits of ID considered in the data base supplied to the CRP, as well as the average ID values taking into account (ID $=\mathrm{ET}_{\mathrm{c}}-P_{\mathrm{e}}$ ) or not (ID $\left.=\mathrm{ET}_{\mathrm{c}}\right)$ the effective rainfall $\left(P_{\mathrm{e}}\right.$, considered as the $70 \%$ of the rainfall collected in the weather station). The data base will be used by the CRP in case irrigation is intended to replace the crop demand. In this work, however, the 5\% threshold value from which $\left(E_{\mathrm{pNI}} / E_{\mathrm{pOI}}\right)_{\mathrm{DOY}}$ was considered by $\mathrm{CU}$ as different from $\left(E_{\mathrm{pNI}} / E_{\mathrm{pOI}}\right)_{\mathrm{DOY}-1}$, was big enough to apply a deficit irrigation in which the crop used part of the readily available water in the soil. Consequently, the data base was not used during the field testing.

Fig. 2 shows the capability of the CRP to both filter and amplify the weak and sometimes noisy output signals from the sap flow probes. The curve shown in Fig. 2a corresponds to the voltage derived from the external pair of thermocouples of one of the probe sets read by MU1, registered with a high performance digital multimeter (Keithley, 2000 , accuracy of $0.003 \%$ reading) before coming into the electronic board of the MU for 
filtering and amplification. The curve shown in Fig. $2 \mathrm{~b}$ was registered with a standard digital multimeter (Iso-Tech IDM73, accuracy of $0.5 \%$ reading) after being filtered and amplified by the MU. This curve, despite having been highly amplified (note differences on the $\mathrm{Y}$-axis scale between Figs. 2a and $2 \mathrm{~b}$ ) and measured with a low precision multimeter, was less noisy than that in Fig. 2a, which indicates the MU's high amplification and filtering performance. We can expect the $t_{\mathrm{z}}$ value calculated by the MU ( $82 \mathrm{sec}$, Fig. $2 \mathrm{~b}$ ) to be more precise than that derived from the curved registered by high performance multimeter (92 sec, Fig. 2a), as the MU's curve was less noisy.

Fig. 3 shows that the sap flow values registered by the CRP followed well the tree transpiration dynamics, calculated as $E_{\mathrm{p}}=\mathrm{ET}_{\mathrm{c}}-E_{\mathrm{s}}, E_{\mathrm{s}}$ being the soil evaporation. The crop coefficient approach was used to calculate the daily values of $\mathrm{ET}_{\mathrm{c}}$ shown in the figure, as mentioned above. Results from previous work on soil evaporation made in the orchard by Fernández and Moreno (1999) and Diaz et al. (2004) were taken into account for calculating the daily values of $E_{\mathrm{s}}$. For the studied period, DOY 128-142, the calculated $E_{\mathrm{s}}$ amounted to $19.8 \%$ of $\mathrm{ET}_{\mathrm{c}}$. This relatively high value of $E_{\mathrm{s}}$ could be explained by the high $\theta$ values of the top soil layers at this time of the year. The fact that the $E_{\mathrm{p}}$ dynamics registered by the MUs echoed the $E_{\mathrm{p}}$ estimated from the atmospheric demand and crop coefficients, indicates that the CRP was able to adequately register $t_{\mathrm{z}}$ in the experimental trees, and to derive reasonable values of $Q$. Whether these estimated $Q$ values were close or not to the actual $Q$ values, has little influence on the functioning of the CRP, since the device calculates ID based on the time course of the $E_{\mathrm{pNI}} / E_{\mathrm{pOI}}$ ratio, not on the actual tree transpiration. The same can be said for any possible effect of time after probe installation on sap flow readings: it is expected that both NI and OI trees would be similarly affected, so the value of the $E_{\mathrm{pNI}} / E_{\mathrm{pOI}}$ ratio will not be affected by this potential source of error.

Table 1 shows the daily ID values calculated and supplied by the CRP, as well as the IDs to replace the crop water needs, calculated with the crop coefficient approach. Soil water measurements made in the orchard by Fernández et al. (2003) indicated that the stock of water in the wet bulbs was around $1400 \mathrm{~L} /$ tree at field capacity. It is generally assumed some $70 \%$ of that water, i.e. $980 \mathrm{~L} /$ tree, can be consumed by the trees before suffering from excessive water stress. The difference between the IDs supplied by the CRP during the studied period, and the IDs estimated to replace the crop water needs amounted to some $600 \mathrm{~L} /$ tree, far from the mentioned amount. This can explain the relatively constant $E_{\mathrm{pNI}} / E_{\mathrm{pOI}}$ ratio registered during the evaluation period (Table 1$)$. The fact that the ratio increased sometimes, with respect to the initial value, could be due to limitations inherent to the CHP method: sap flows are recorded for a few minutes every half hour, influence of probe location, etc.

\section{CONCLUSIONS}

The prototype of the CRP tested here was able to make reliable and robust sap flow readings, to derive ID values according to the designed algorithm, and to control the irrigation pump and the electrovalve for supplying the calculated ID. In the field the device behaved as expected, and according to the chosen deficit irrigation strategy. Further field test are needed before concluding that the CRP is able to improve irrigation control, as compared to standard irrigation scheduling techniques.

\section{ACKNOWLEDGEMENTS}

This work has been funded by the IFAPA, Consejería de Innovación, Ciencia y Empresa de la Junta de Andalucía, research project ref. C03-056. 


\section{Literature Cited}

Allen, R., Pereira, L.S., Raes, D. and Smith, M. 1998. Crop evapotranspiration. Guidelines for computing crop water requirements. FAO Irrigation and Drainage Paper 56. FAO, Rome, Italy.

Diaz-Espejo, A., Verhoef, A., Fernández, J.E., Villagarcía, L. 2004. Use of high resolution weighing lysimeters to estimate main driving variables related to soil evaporation in a drip irrigated olive orchard. Proc. 5th Internacional Symposium on Olive Growing. Izmir, Turkey. 27 September - 2 October. p. 30.

Fernández, J.E., Diaz-Espejo, A., Infante, J.M., Durán, P., Palomo, M.J., Chamorro, V., Girón, I.F. and Villagarcía, L. 2006a. Water relations and gas exchange in olive trees under regulated déficit irrigation and partial rootzone drying. Plant Soil, in press.

Fernández, J.E., Durán, P.J., Palomo, M.J., Diaz-Espejo, A., Chamorro, V. and Girón, I.F. 2006b. Calibration of sap flow measurements by the compensation heat-pulse method in olive, plum and orange trees: relations with xylem anatomy. Tree Physiol. 26:719-728.

Fernández, J.E. and Moreno, F. 1999. Water use by the olive tree. J. Crop Prod. 2(2):101162.

Fernández, J.E., Palomo, M.J., Diaz-Espejo, A., Clothier, B.E., Green, S.R., Girón, I.F. and Moreno, F. 2001. Heat-pulse measurements of sap flow in olives for automating irrigation: tests, root flow and diagnostics of water stress. Agri. Water Mgt. 51:99123.

Fernández, J.E., Palomo, M.J., Diaz-Espejo, A. and Girón, I.F. 2003. Influence of partial soil wetting on water relation parameters of the olive tree. Agronomie 23:545-552.

Giorio, P. and Giorio, G. 2003. Sap flow of several olive trees estimated with the heatpulse technique by continuous monitoring of a single gauge. Environ. Exp. Bot. 49:920.

Goldhamer, D.A. and Fereres, E. 2004. Irrigation scheduling of almond trees with trunk diameter sensors. Irrig. Sci. 23:11-19.

Green, S.R., 1998. Flow by the heat-pulse method. HortResearch Internal rep. 1998/22. HortResearch, Palmerston North, New Zealand.

Green, S.R., Clothier, B.E. and Jardine, B. 2003. Theory and practical application of heatpulse to measure sap flow. Agron. J. 95:1371-1379.

Jones, H.G. 2004. Irrigation scheduling: advantages and pitfalls of plant-based methods. J. Exp. Bot. 407:2427-2436.

Klein, I. 2004. Scheduling automatic irrigation by threshold-set soil matric potential increases irrigation efficiency while minimizing plant stress. Acta Hort. 664:361-368.

Luthra, S.K., Kaledhonkar, M.J., Singh, O.P. and Tyagi, N.K. 1997. Design and development of an auto irrigation system. Agri. Water Mgt. 33:169-181.

Miranda, F.R., Yoder, R.E., Wilkerson, J.B. and Odhiambo, L.O. 2005. An autonomous controller for site-specific management of fixed irrigation systems. Comput. Electron. Agr. 48:183-197

Nadezhdina, N. and Cermak, J. 1997. Automatic control unit for irrigation systems based on sensing the plant water status. An. Inst. Sup. Agronom. 46:149-157.

Nogueria, L.C., Dukes, M.D., Haman, D.Z., Scholberg, J.M. and Cornejo C. 2003. Data acquisition system and irrigation controller based on CR10X datalogger and TDR sensor. Soil Crop Sci. Soc. Florida Proc. 62:38-46.

Williams, D.G., Cable, W., Hultine, K., Hoedjes, J.C.B., Yepez, E.A., Simonneaux, V., Er-Raki, S., Boulet, G., de Bruin, H.A.R., Chehbouni, A., Hartogensis, O.K. and 
Timouk, F. 2004. Evapotranspiration components determined by stable isotope, sap flow and eddy covariance techniques. Agric. Forest Meteorol. 125:241-258.

\section{$\underline{\text { Tables }}$}

Table 1. Results from the field test carried out with the CRP at the beginning of the irrigation season. DOY $=$ day of year $\left(\mathrm{DOY} 128=8\right.$ May); Mean $E_{\mathrm{pNI}} / E_{\mathrm{pOI}}=$ mean transpiration ratio between normally-irrigated and over-irrigated trees; Threshold $=$ difference between the mean $E_{\mathrm{pNI}} / E_{\mathrm{pOI}}$ value of the current day and that of the previous day; Supplied ID = irrigation dose calculated and supplied by the CRP $(*=$ values given by the user); Estimated ID = values of ID estimated with the crop coefficient approach to replace the crop water needs.

\begin{tabular}{llllc}
\hline DOY & Mean $E_{\mathrm{pNI}} / E_{\mathrm{pOI}}$ & $\begin{array}{l}\text { Threshold } \\
(\%)\end{array}$ & $\begin{array}{l}\text { Supplied ID } \\
(\mathrm{L} / \text { tree/day })\end{array}$ & $\begin{array}{c}\text { Estimated ID } \\
(\mathrm{L} / \text { tree/day) }\end{array}$ \\
\hline 128 & 0.92 & & $90.0^{*}$ & 80.7 \\
129 & 0.89 & -2.7 & $90.0^{*}$ & 85.9 \\
130 & 0.88 & -0.9 & 81.0 & 89.2 \\
131 & 0.84 & -5.0 & 89.1 & 65.8 \\
132 & 0.85 & 1.7 & 80.2 & 88.5 \\
133 & 0.88 & 2.6 & 64.2 & 95.0 \\
134 & 0.85 & -2.6 & 51.3 & 85.9 \\
135 & 0.87 & 1.7 & 41.1 & 85.8 \\
136 & 0.86 & -0.9 & 32.8 & 108.9 \\
137 & 0.85 & -1.7 & 26.3 & 62.9 \\
138 & 0.83 & -1.7 & 21.0 & 101.1 \\
139 & 0.87 & 4.3 & 16.8 & 94.1 \\
140 & 0.86 & -0.9 & 13.5 & 108.1 \\
141 & 0.88 & 1.8 & 10.8 & 86.2 \\
142 & 0.88 & 0.0 & 8.6 & \\
\hline
\end{tabular}

\section{Figures}

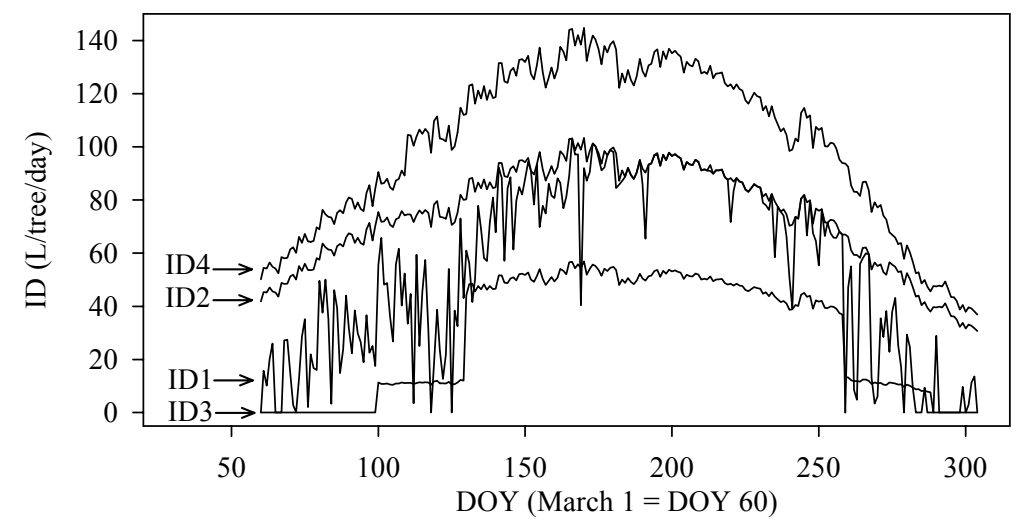

Fig. 1. Daily irrigation doses (ID) of the data base provided to the CRP, estimated for the whole irrigation season (March 1 - October 31) from 34 years of weather records. ID1 $=$ crop evapotranspiration minus effective rainfall; ID2 $=$ crop evapotranspiration; ID3 = minimum value below which the applied ID will be ID2, and not the one calculated by the CRP; ID4 = maximum ID value over which the applied ID will be ID2 and not the one calculated by the CRP. 


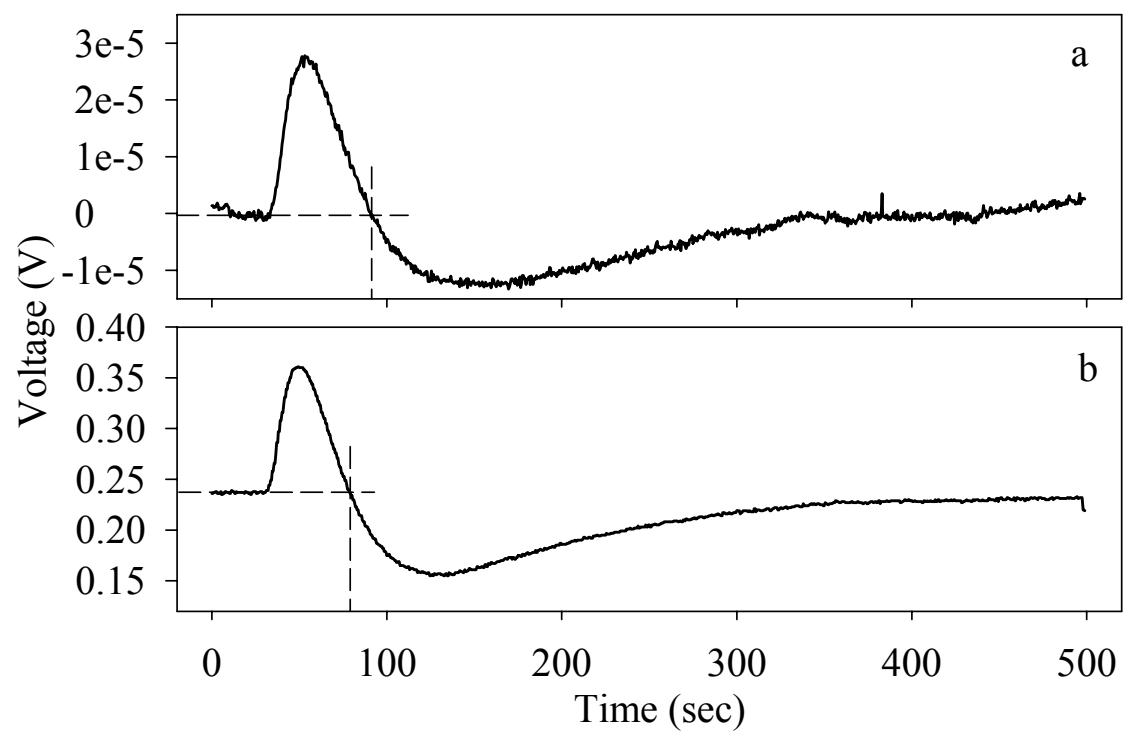

Fig. 2. Output voltage from the outer pair of thermocouples of one of the probe sets read by the Measurement Unit 1, before (a) and after (b) being amplified and filtered by the CRP.

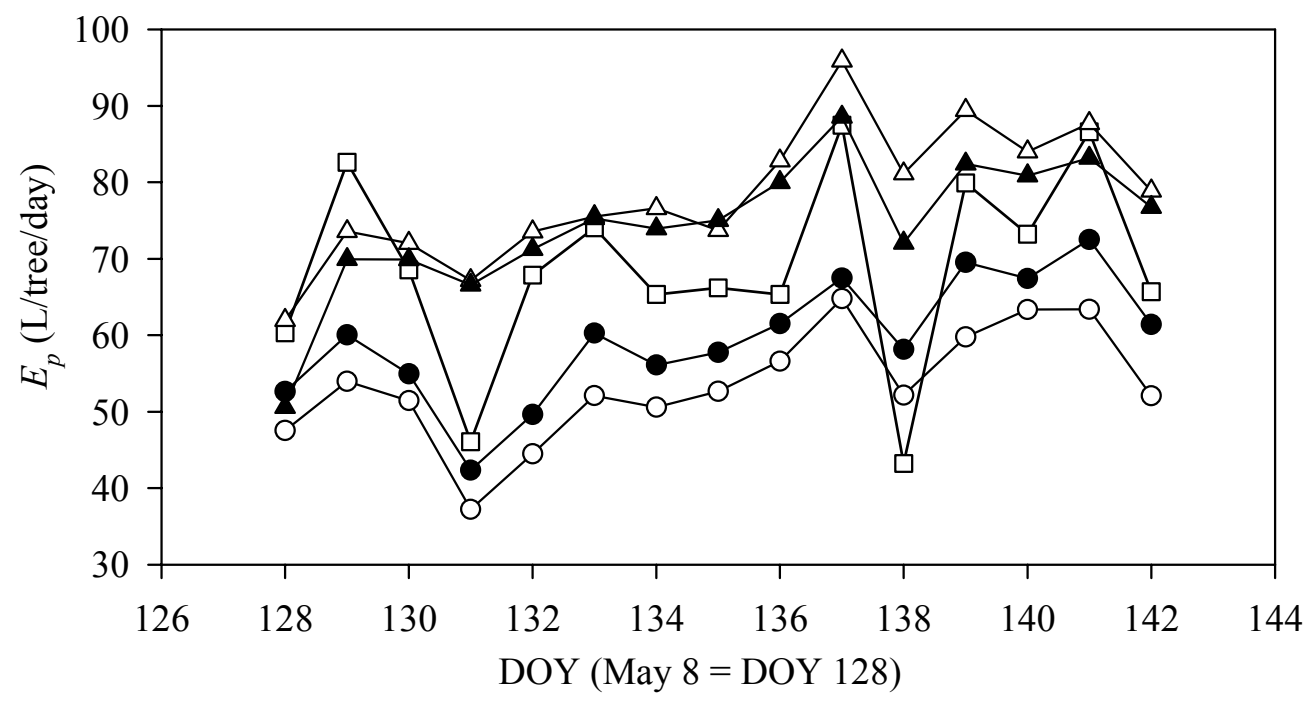

Fig. 3. Values of daily tree transpiration $\left(E_{\mathrm{p}}\right)$ calculated with the crop coefficient approach (squares), at the beginning of the irrigation period. Also shown are the $E_{\mathrm{p}}$ values calculated by the Control Unit from the sap flow values registered by Measurement Unit (MU) 1 (circles) and MU2 (triangles). Open symbols correspond to values registered in the normally-irrigated trees, while closed symbols correspond to measurements in over-irrigated trees. Values of MU3 were in between those of MU1 and MU2. DOY = day of year. 